Original Research Paper

\title{
Development of a Magnetorheological Finishing Machine for Small-Bore Part of Irregular Shape and Experimental Study
}

\author{
Wang Tingzhang, Chen Mingjun, Liu Henan and Xu Jiang \\ Center for Precision Engineering, Harbin Institute of Technology, Harbin, 150001, China
}

\author{
Article history \\ Received: 08-06-2015 \\ Revised: 11-06-2015 \\ Accepted: 11-06-2015 \\ Corresponding Author: \\ Chen Mingjun \\ Center for Precision Engineering, \\ Harbin Institute of Technology, \\ Harbin, 150001, China \\ Email: chenmj@hit.edu.cn
}

\begin{abstract}
Magnetorheological finishing machine tool with small ball-end permanent-magnet polishing head is proposed as a method to solve the problem that small-bore parts of irregular shape with small curvature radius concave surface cannot be polished by traditional magnetorheological finishing machine tool. The four-axis linkage magnetorheological finishing machine tool with modular open numerical system and easy-operating man-machine interactive interface is developed. Then the machine tool is used to study the removal characteristics on machining parameters. It is indicated that the removal rate is not sensitive to processing time. When the angle between the polishing head and the workpiece is larger, the removal rate is higher. The surface roughness of workpiece can be less than 3 $\mathrm{nm}$, which is machined by magnetorheological polishing with a small permanent magnet ball-end tool.
\end{abstract}

Keywords: Magnetorheological Finishing, Small Ball-End Tool, Process Experiment

\section{Introduction}

In the early 1990s, based on the studying of smart fluid, Kordonski with his cooperators invented Magnetorheological Finishing (MRF) (Jacobs et al., 1999). It is a deterministic polishing technology controlled by computer. So it can not only polish workpiece with no subsurface damage, but also can remove the surface crack and surface/subsurface residual stress, produced by grinding (Arrasmith et al., 2001).

In Kordonski (1996) developed the first prototype for MRF. Then magnetorheological finishing machine tools were produced and they have already become commercial products in America (Kordonski et al., 1996). In recent years, many scholars have done researches to develop new machine tools for MRF. QED produced the latest minitype polishing tools Q22-Y with 20 and $50 \mathrm{~mm}$ polishing wheels (Harris, 2011). Jiao et al. (2013) developed a machine tool for MRF using ring permanent-magnet as excitation and Ren et al. (2014) proposed a new MRF, named BeltMRF to improve the material removal rate.

By far, existing magnetorheological finishing machine tools with mature technology generally adopt construction of polishing wheel. They can be used for polishing typical plane and cambered components, but cannot polish components of irregular shape with small curvature radius aspheric surface. So in this study a novel structured four-axis linkage magnetorheological finishing machine tool with small ball-end permanent-magnet polishing head is proposed and it can polish small-bore parts of irregular shape with small curvature radius concave surface and obtain high precision and fine surface quality.

\section{Magnetorheological Finishing Theory}

As the magnetorheological fluid is in magnetic field, there is magnetorheological effect. Then magnetorheological finishing uses this effect to polish the workpiece. Figure 1 shows magnetorheological finishing theory. Magnetorheological fluid is composed of base fluid, magnetic-particle, stabilizer and ultra-fine abrasive or polishing powder. When the magnetorheological fluid is in the magnetic field, magnetorheological effect is produced and its ostensible concentration will increase in a few milliseconds. Tt will adhere to polishing wheel and become a polishing band in solid state. When it rotates with the polishing wheel, the band will contact 
workpiece. The surface material is removed by shear stress (Su et al., 2014), while polishing wheel and workpiece move in relative way. When magnetorheological fluid leaves the magnetic field, it will return to liquid state and can be recycled.

In this study, a magnetorheological finishing tool with small ball-end permanent-magnet polishing head is developed and high-energy, rare-earth permanentmagnet is used to produce magnetic field. As the magnetorheological liquid flows into the magnetic field, it will produce magnetorheological effect and polish the workpiece. The small ball-end polishing head can polish small curvature radius concave surface. Small ball-end permanent-magnet polishing head and polishing process is showed in Fig. 2 .

\section{Develop the Construction of Magnetorheological Finishing Machine Tool}

A vertical gantry type four-axis linkage magnetorheological finishing machine tool is developed It includes three linear movement axes, one spindle, workpiece axis and polishing wheel axis. Workpiece axis and polishing wheel axis are not included in the fouraxis linkage. $\mathrm{X}$ and $\mathrm{Y}$ axis are stacked up to bear the workpiece axis and to realize two-dimension motion in the horizontal direction. $\mathrm{C}$ axis is hung on the motion unit of $\mathrm{Z}$ axis by a triangular linker with upside down and it can take the polishing axis rotate around the $\mathrm{Z}$ axis together. The angle between polishing wheel axis and horizontal plane is 40 degrees, which would help to avoid interference in the process of polishing irregular shaped parts. Figure 3 shows the main parts of the developed magnetorheological finishing machine tool.

As mentioned above, the magnetorheological finishing machine is composed of these parts: (1) Machine tool that includes the machine base, gantry and motor units; (2) numerical system, which can realize four-axis linkage; (3) assistant devices, such as vibration

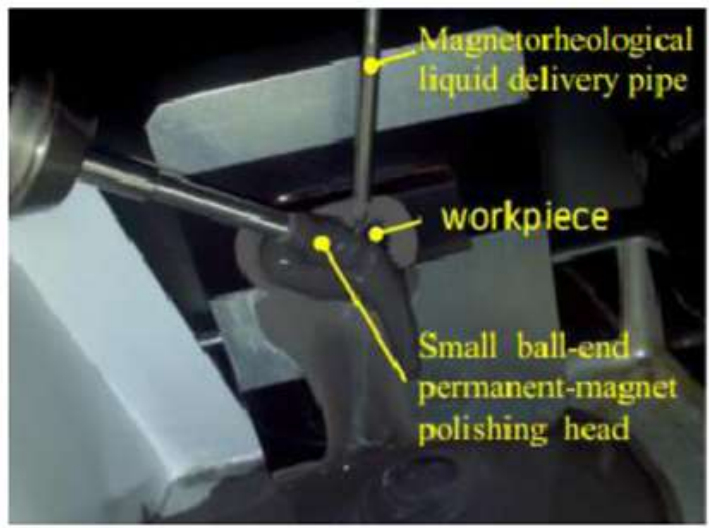

(a) isolation table, CCD tool setting and monitoring device, magnetorheological fluid cycle system and the organ shields for X-Y motor unit.

The designed precision of this machine tool is $2 \mu \mathrm{m}$. So the machine tool is placed on precision vibration isolation table and the granite is selected as base to absorb vibration and improve the accuracy. Due to the designed precision, high motion precision of very motor unit is needed. Select linear motor driven high-precision table of Parker as X-Y linear axis and the resolution of the table is $0.1 \mu \mathrm{m}$. $\mathrm{Z}$ axis is screw driven precision linear ball bearing table. The coreless direct drive rotary motor of Akbisis which will achieve high precision at low speed is used as $\mathrm{C}$ rotation unit. The high-speed and high-precision ceramic bearing spindle is used as the polishing spindle and workpiece spindle.

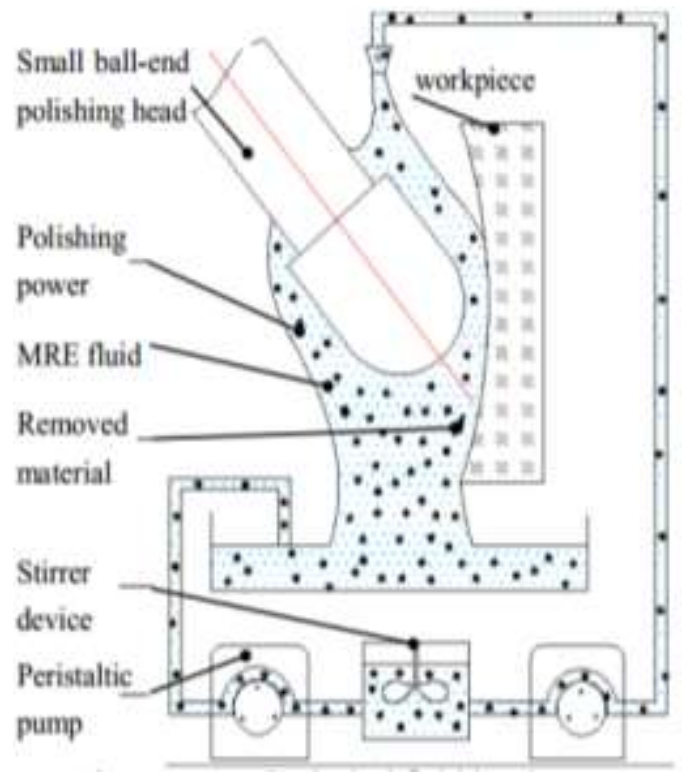

Fig. 1. Magnetorheological finishing theory

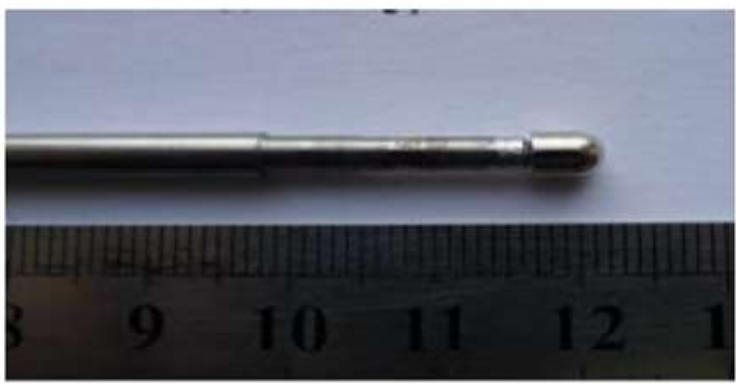

(b)

Fig. 2. Polishing process and ball-head polishing head (a) Polishing process (b) Small ball-end polishing head 


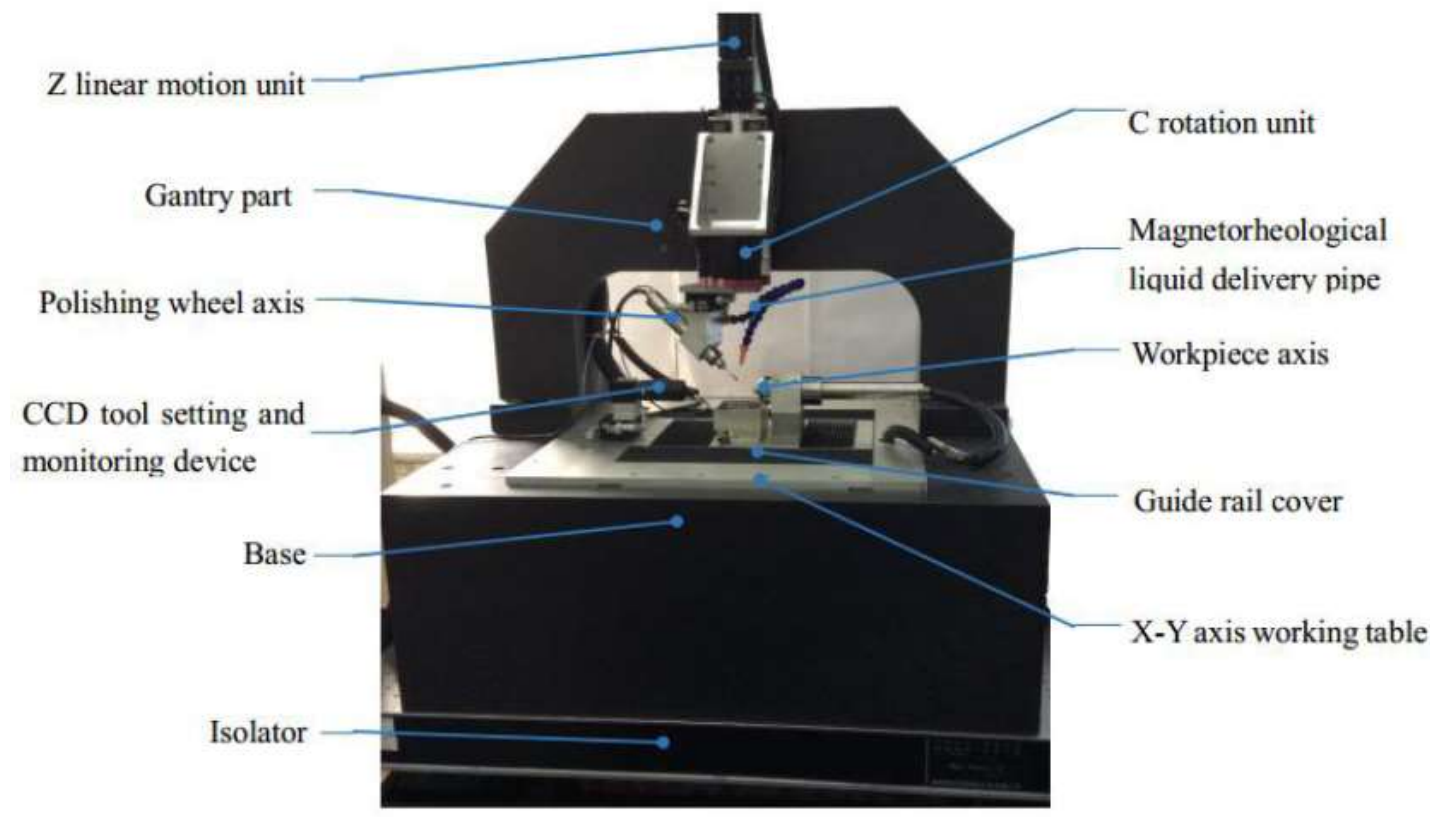

Fig. 3. Magnetorheological finishing machine for small- bore part of irregular shape

\section{Numerical System of the Magnetorheological Finishing Machine}

According to the processing requirements, a numerical system hardware platform is built. The main parts of the platform are Industrial Personal Computer (IPC) and Universal Motion and Automation Controller (UMAC). IPC is used as upper computer and UMAC is lower computer. They together with servo drivers, servo motors, grating scales and encoders compose modular open system.

At the same time, based on the communication between the upper and lower computers, relevant variables, on-line commands and development theory of UMAC used for second development of the system, develop simple and easy-operating man-machine interactive interface. The development is in Visual C++ compiler environment and accords to requirement of realistic polishing. The main window of numerical system is showed in Fig. 4.

\section{Effects about Removal Characteristics on Machining Parameters}

\section{Effects of the Removal Time on the Removal Rate}

The influence of removal time on the removal efficiency is discussed with the removal time increasing from $5 \mathrm{~min}$ to $30 \mathrm{~min}$. As shown in Fig. 5, the relationship between the removal depth and processing time is approximately linear. And the linear correlation is
0.994 calculated by the experimental results. It is indicated that the material removal is stable and removal rate isn't sensitive to the processing time.

\section{Effects of the Swing Angle on the Removal Rate}

The influence of the angle between the polishing head and the workpiece on the removal rate is discussed with the angle increasing from $10^{\circ}$ to $50^{\circ}$, while other parameters are designated as constant. As shown in Fig. 6, when the angle between the polishing head and the workpiece is larger, the removal rate is larger. However the actual surface profile is not Gausee shape, when the angle is larger than $30^{\circ}$, because there is a inflection point in surface profile. So the best angle between the polishing head and the workpiece in polishing process is $30^{\circ}$.

\section{Effects on Surface Roughness of Workpiece}

When the workpiece is polished by the machine tool with small ball-end permanent-magnet polishing head, its surface roughness can be less than $3 \mathrm{~nm}$. In this experiment, the workpiece is $\mathrm{K} 9$ glass bar and its diameter is $6 \mathrm{~mm}$. The workpiece is reciprocally processed in the range of $4 \mathrm{~mm}$ for $45 \mathrm{~min}$ at an speed of $0.03 \mathrm{~mm} \mathrm{sec}{ }^{-1}$. The processing parameters are that the minimum machining gap, spindle speed, included angle and size of powder particle are set to be $0.10 \mathrm{~mm}, 6000$ $\mathrm{r} / \mathrm{min}, 30^{\circ}$ and $8 \mathrm{um}$, respectively. Then the results is shown in Fig. 7a) shows the surface profile and Fig. 7b) shows the surface roughness. 


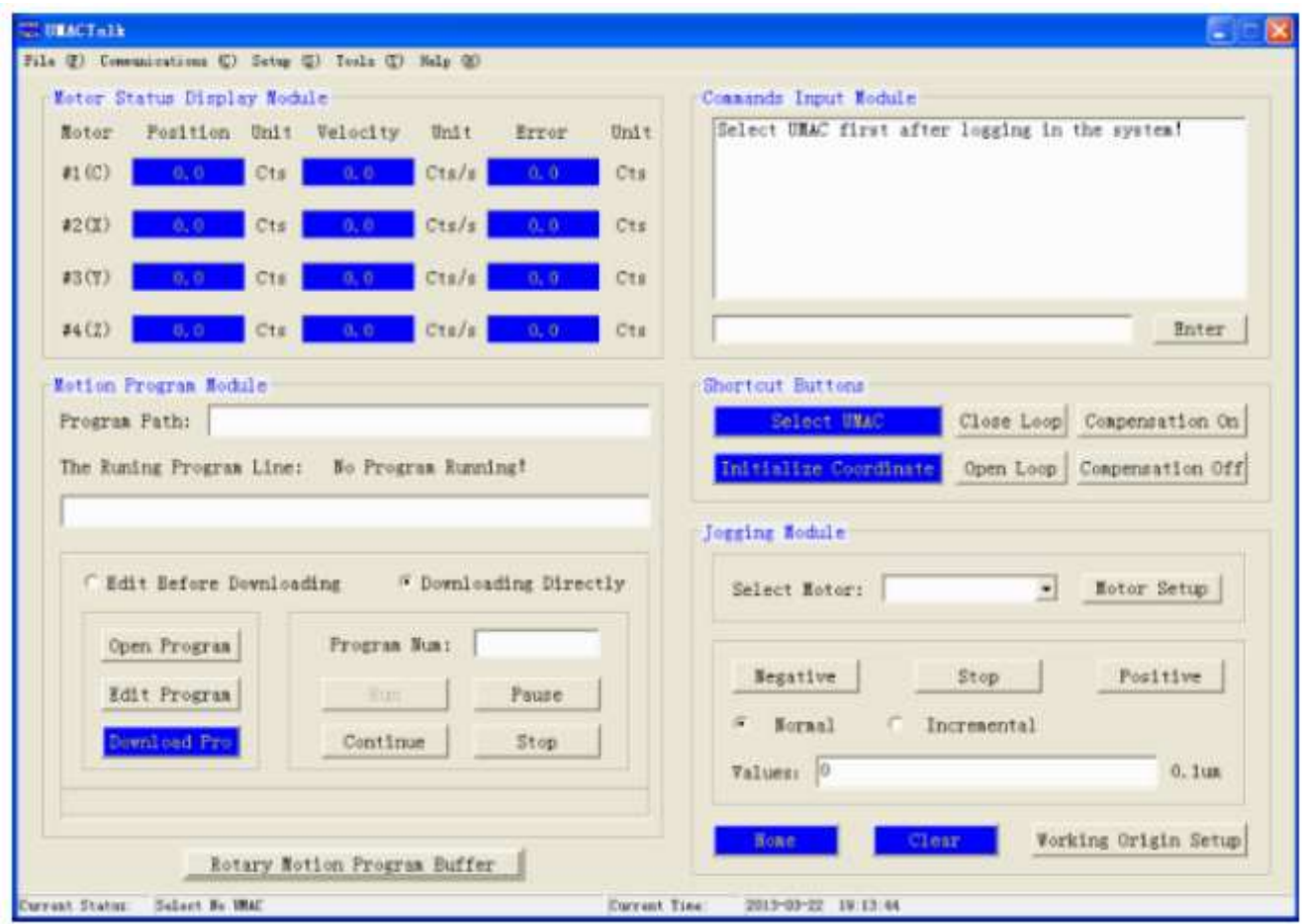

Fig. 4. The main window of numerical system

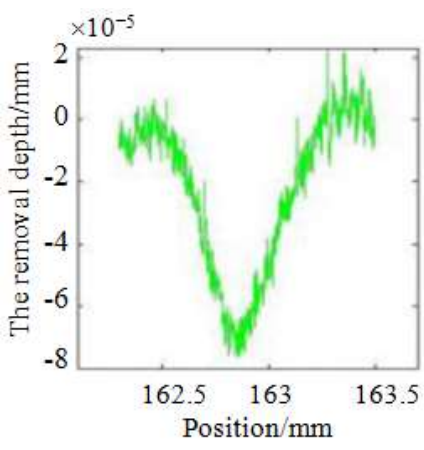

(a)

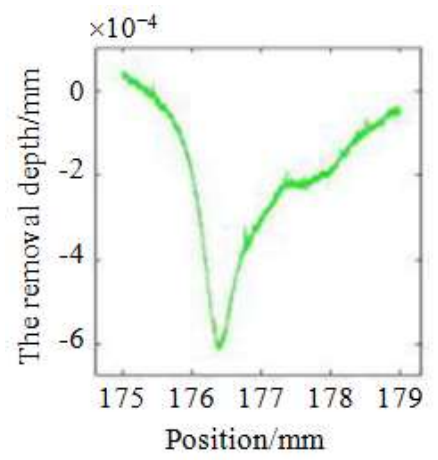

(e)

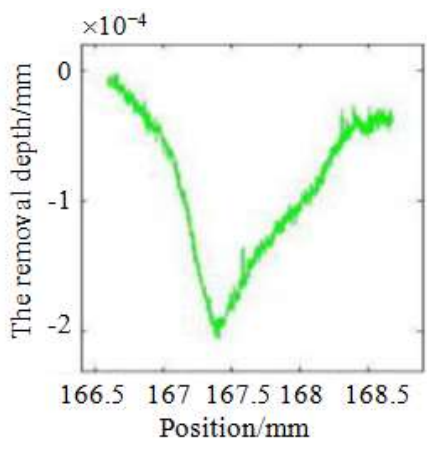

(b)

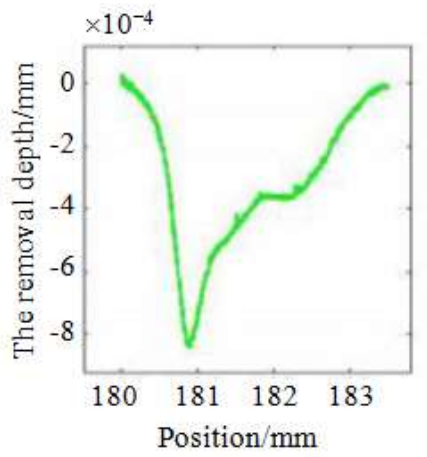

(f)

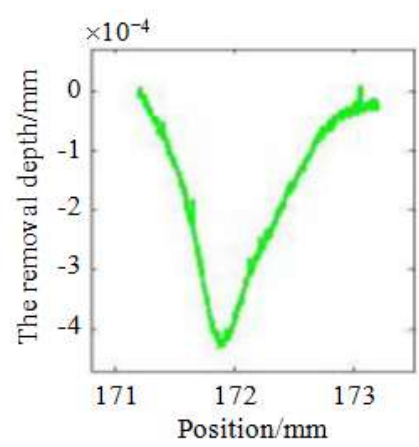

(c)

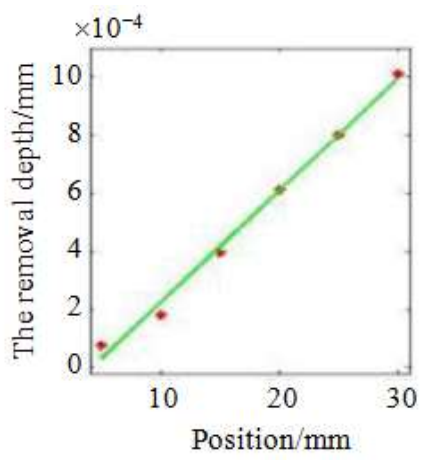

(g)

Fig. 5. The effect of the removal time on the removal efficiency (a) the removal time 5 min (b) the removal time 10 min (c) the removal time $15 \mathrm{~min}$ (e) the removal time $20 \mathrm{~min}$ (f) the removal time $25 \mathrm{~min}$ (g) the relationship between the removal time and removal 


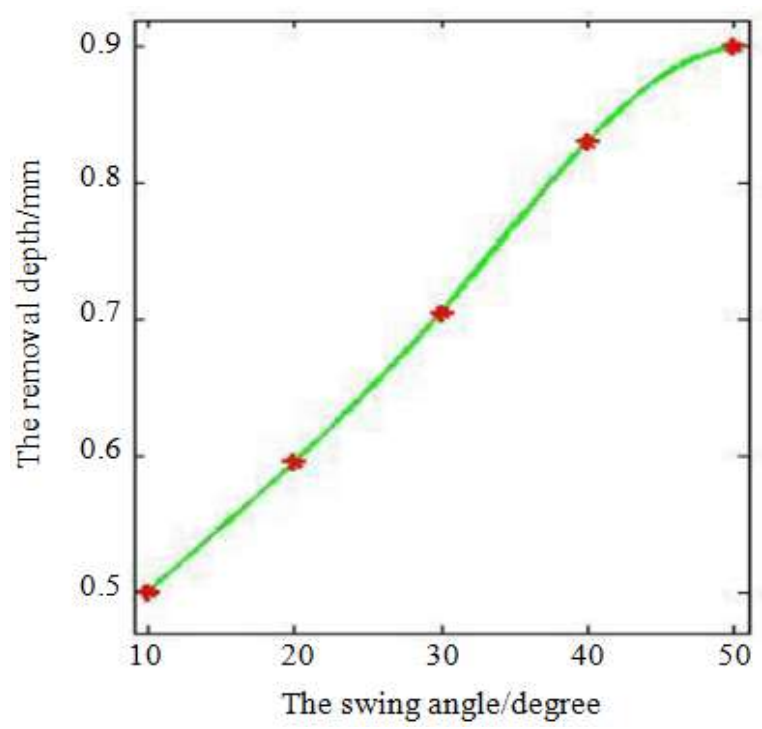

Fig. 6. The relationship between the swing angle and removal depth

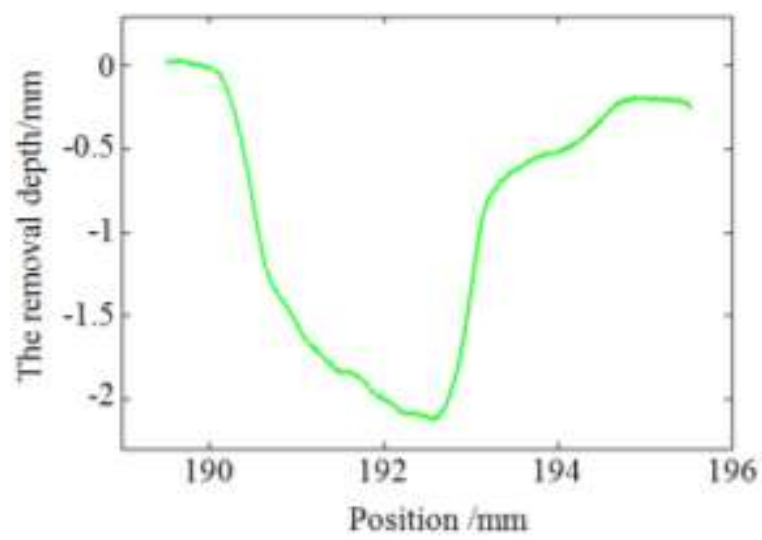

(a)

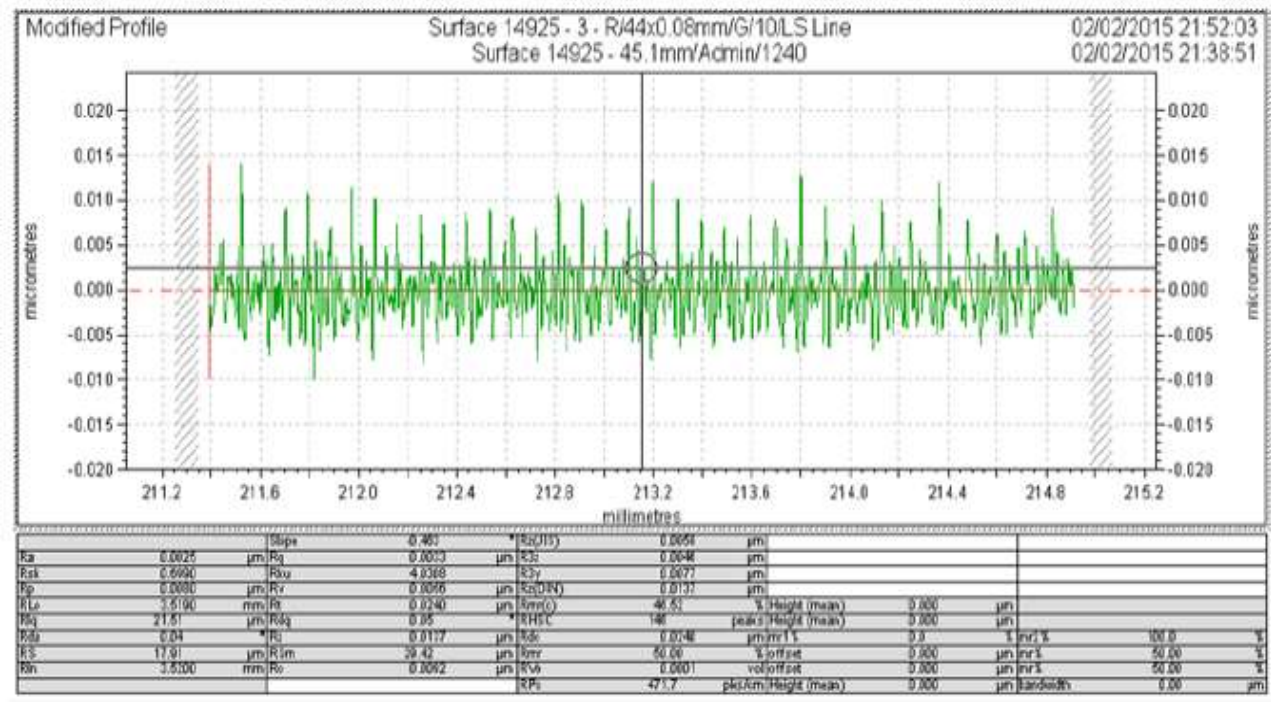

(b)

Fig. 7. The result of reciprocating polishing (a) the surface profile (b) the surface roughness 


\section{Conclusion}

A novel magnetorheological finishing machine is developed with the small ball-end permanent-magnet polishing head. It can realize four-axis linkage. And the polishing spindle is inclined $45^{\circ} \mathrm{C}$ relative to the horizontal plane, so it can succeed in avoiding interference when the small curvature radius concave surface is polished. At the same time, the numerical system with simple and easy-operating man-machine interactive interface is developed.

The removal characteristics of magnetorheological finishing is studied with the machine developed. Experimental results show that removal rate is not sensitive to processing time and the linear correlation is 0.994 , besides, the optimal angle between the polishing head and the workpiece is $30^{\circ}$. At the same time, when the small ball-end permanent-magnet polishing head is used to polish the $\mathrm{K} 9$ glass bar, the best roughness can be less than $3 \mathrm{~nm}$.

\section{Acknowledgement}

The authors would like to thank the national hightech R\&D program of China (863 Program) (No. 2015AA043301).

\section{Authors Contribution's}

Wang Tingzhang: Participated in all experiments and contributed to the writing of the manuscript.

Chen Mingjun: Designed the research plan and organized the study.

Liu Henan: Coordinated the mouse work.

Xu Jiang: Coordinated the data-analysis.

\section{Ethics}

This article is original and contains unpublished material. The corresponding author approved the manuscript and confirms that no ethical issues involved.

\section{References}

Arrasmith, S.R., S.D. Jacobs, J.C. Lambropoulos, A. Maltsev and D. Golini et al., 2001. The use of Magnetorheological Finishing (MRF) to relieve residual stress and subsurface damage on lapped semiconductor silicon wafers. Proc. SPIE, 4451: 286-294.

Harris, D.C., 2011. History of Magnetorheological Finishing. Proceedings of the Window and Dome Technologies and Materials, (DTM' 11), SPIE, pp: 1-22. DOI: $10.1117 / 12.882557$

Jacobs, S.D., S.A. Arrasmith, I.A. Kozhinova, L.L. Gregg and A.B. Shorey et al., 1999. An overview of Magnetorheological Finishing (MRF) for precision optics manufacturing. Ceramic Trans., 102: 185-199.

Jiao, L., Y. Wu, X. Wang, H. Guo and Z. Liang, 2013. Fundamental performance of magnetic compound fluid (MCF) wheel in ultra-fine surface finishing of optical glass. Int. J. Machine Tools Manuf., 75: 109-118. DOI: 10.1016/j.ijmachtools.2013.09.003

Kordonski, W.I., S.D. Jacobs, D. Golini, E. Fess and D. Strafford et al., 1996. Vertical wheel magnetorheological finishing machine for flat, convex and concave surfaces. Optical Fabricat. Test. Tech. Digest Ser., 7: 146-149.

Ren, K., X. Lou, L. Zheng, Y. Bai and L. Li et al., 2014. Belt-MRF for large aperture mirrors. Opt. Express, 22: 19262-19276. DOI: 10.1364/OE.22.019262, PMID: 25321011

Su, Y.R., D. Li, H.N. Liu, M.J. Chen and H. Peng, 2014. Experiment research of polishing capability of magnetorheological finishing with a small permanent magnet ball-end tool. Adv. Machin. Manuf. Technol. 589-590: 497-501.

DOI: 10.4028/www.scientific.net/KEM.589-590.497 